\title{
SUPPORTING ONLINE ADJUNCT FACULTY: A VIRTUAL MENTORING PROGRAM
}

Maria Puzziferro-Schnitzer

Associate Dean, Virtual College

Florida Community College at Jacksonville

Jeff Kissinger

Instructional Program Manager, Virtual College

Florida Community College at Jacksonville

\begin{abstract}
Because of growing demand for online courses, staffing and faculty support issues can become major obstacles to growth and instructional quality. In 2004, Florida Community College at Jacksonville (FCCJ) was awarded an Effective Practices Award at the Sloan-C conference in Orlando, Florida for its Virtual Adjunct Mentoring program. This paper will provide the background, current program organization, and future directions of the program.
\end{abstract}

\section{KEYWORDS}

Online Adjuncts, Online Faculty

\section{INTRODUCTION}

The growth of online learning continues steadily. According to the 2003 Sloan Survey of Online Learning, the number of students taking at least one online course is projected to increase by 19.8 percent over the one-year period from Fall 2002 to Fall 2003, to include a total of 1.9 million students [1]. For public institutions, the National Center for Education Statistics reports that in 2000-2001, 90 percent of public 2-year and 89 percent of public 4-year institutions offered distance education courses [2].

The student demand for online courses has outpaced the full-time instructional capacity at many colleges and universities, creating an instructional gap that adjunct faculty readily fill. The 2003 Sloan Survey also cites that convincing traditional faculty of the benefits of online teaching and learning remains a challenge. Colleges and universities continue to work steadily to provide professional development and incentives to involve full-time faculty in distance learning.

Virtual adjuncts have eagerly stepped up to fill the staffing void, thereby enabling institutions to respond promptly to market demand. By recruiting outside of the local community, institutions are able to attract a fascinating and highly diverse group of faculty, who are not only diverse geographically, but also bring a variety of backgrounds, motivations, and experience. This national network of professionals connects students to learning experiences, knowledge, resources, and scholars across the country.

Faculty recruitment, training, support and development are critical components to ensure instructional quality. Providing adequate and timely support for new faculty can be challenging because of staffing 
shortages. The Virtual Adjunct Mentoring program has enabled FCCJ to expand distance education course offerings and provide a high level and quality of instructional support to new adjuncts by adopting the peer-mentoring approach.

\section{ONLINE COURSES AT FCCJ: A BRIEF HISTORY}

Over the past 3 years, FCCJ has experienced steady, considerable growth in online enrollments. The Virtual College program had 17,495 enrollments in the 2002-2003 academic year. Enrollments rose to 23,700 for the 2003-2004 academic year. The enrollment for the 2004-2005 year (still in session) has already surpassed 32,000.

During this time, the Virtual College at FCCJ began recruiting adjunct faculty nationally in order to build a pool of qualified, trained faculty to sustain growth. At this time, Virtual College has more than 200 active adjunct faculty members, and more than 80 percent reside outside of the state of Florida. Recruitment efforts continue steadily, and applications are received and reviewed on an ongoing basis.

\section{VIRTUAL MENTORING}

The term "learning community" has become universal in education, and refers to a variety of arrangements where individuals continuously share resources and seek to apply what they have learned to their own practice. Astuto [3] has identified the professional community of learners, who are professionals seeking to enhance their own effectiveness, and promote quality in teaching and learning. Peer-based sharing is the most effective model for providing support in the professional learning community [4].

The Virtual Mentoring Program is the heart of the professional online teaching and learning community at FCCJ. The mentoring paradigm fits nicely with the culture of online learning, as online teaching methodologies emphasize facilitation and mentoring of students. This represents a relatively new and foreign teaching philosophy for some traditional faculty.

The goal of the Virtual Adjunct Mentoring program is to provide personalized, collegial support for a specified number of new online adjunct faculty. Virtual Mentors monitor orientation of new adjuncts assigned to them, maintain a peer-based support relationship, and assist with administrative issues related to the course and other processes.

The Virtual Mentoring Program consists of Lead Mentors and Virtual Mentors, paid a stipend for each semester of service. Lead Mentors must be full-time faculty, and Virtual Mentors may be full- or parttime faculty who have taught in the Virtual College program for at least one year of consecutive assignments. The involvement of full-time faculty in the mentoring program is an important aspect of the program. Generally, there are limited opportunities for adjunct and full-time faculty to interact. In the distance education environment, this estrangement may be even more pronounced because of physical separation, as well as the relative newness of distance education. Engaging full-time and part-time faculty in mentoring relationships helps to begin to break down the traditional barriers between the two.

Mentors' individual expertise is identified to address specific instructor populations and disciplines. Mentors are matched to new adjuncts based on software expertise and discipline area. 
Each Virtual Mentor is assigned up to 10 new online adjuncts. The specific duties of the mentors are to:

1. Act as a liaison between the administration and the adjunct.

2. Develop professional relationships with new adjuncts through proactive emails and discussion forum contacts.

3. Provide help and share resources, ideas and opportunities.

4. Facilitate an online orientation course. All new adjuncts are required to go through and complete the required orientation assessments before teaching online.

5. Communicate processes for and monitor compliance with administrative processes and procedures.

6. Act as a point of contact for questions/advice about teaching, pedagogy, and use of the learning management systems.

7. Create courseware and knowledge modules as needed.

Lead Mentors provide oversight and coordination among the Virtual Mentors. Lead Mentors conduct meetings and collect any important data or feedback about mentoring activities. Lead Mentors may also make recommendations to the Associate Dean about the evaluation, continuing assignment, or professional development of adjunct faculty. In addition, Lead Mentors provide guidance to new Virtual Mentors and coach them on how to build effective peer relationships and mentor effectively. Lead Mentors, who are full-time faculty members, take the leadership role in this function, fostering a sense of commitment, pride, professionalism, and awareness associated with the home institution.

In addition to assigned mentoring relationships, Virtual Mentors also moderate an adjunct discussion board, focusing on topics related to online teaching and learning; individuals are invited to share techniques, resources and reflections on teaching and learning. Each of the numerous discussion threads are divided into specific subjects and topics, thus allowing the busy instructor quick access to the needed information or expert. Each term, an online faculty member is invited to host and facilitate a professional development discussion on a topic of his or her expertise. Recent topics have included: "A Veteran Instructor's Perspective on Teaching Online," "Student Motivation in the Online Classroom," "Rehumanizing the Learning Space," and "Employing Hybrid Instructional Strategies." Various approaches to introduce topics have been used to engage participants including audio mini-lectures, media-rich presentation modules, and audioblogger ${ }^{\circledR}$ authoring.

\section{PROGRAM EFFECTIVENESS AND THE FUTURE OF VIRTUAL ADJUNCT MENTORING}

Online adjunct faculty play a major role in the future of online learning at FCCJ. Already more than 80 percent of online courses are taught by adjuncts, and this number rises as enrollment continues to grow and more faculty are recruited.

In a Spring 2004 program effectiveness survey of adjunct faculty, it was found that more than 70 percent of the adjunct faculty were teaching at other colleges and universities across the United States in addition to FCCJ. And, more than 35 percent were adjunct "freelancers," by choice. One unique characteristic that could potentially pose challenges to the employing institution of numerous online adjuncts is their unknown, possibly colossal work load [5]. With these emerging divides and unknowns, it is essential for the institution to be cognizant and proactive, instilling meaningful relationships amongst remote faculty for: curricular consistency, instructional quality, and the reputations of its courses and programs of study. 
The Spring 2004 survey also revealed that 72 percent of new adjuncts found the Virtual Mentors helpful. Adjuncts who were newer to online teaching (fewer than two years total online teaching experience) reported the most positive comments about the Virtual Mentors.

At present, the program is continuing for the 2004-2005 academic year with three major projects. First, a comprehensive Adjunct Resource website is being developed, with bulletin boards and professional development modules created and contributed by online faculty. Second, during the Summer 2005 a comprehensive handbook and online training module is being developed for new mentors to provide guidance and support for building effective mentoring relationships. Finally, evaluation and assessment processes are being put in place to collect ongoing data about the quality of mentor relationships and support. Then, research will be conducted to compare success rates and instructor satisfaction of classes where the instructor has been mentored with classes with no mentoring support.

\section{SUMMARY/CONCLUSIONS}

There is no doubt that online course delivery has become a large growth area for colleges [1]. With this growth, many institutions in higher education have been struggling to keep up with the demand while ensuring their high institutional standards and maintaining a burgeoning, diverse, and many times geographically-removed instructional community.

The FCCJ Virtual College Mentor Program has been one successful strategy to address this climate of change, growth, and subsequent challenges. It continues to be an iterative work-in-progress purposely designed as to be nimble and responsive to the current, forthcoming, and yet unknown, issues and challenges accompanying online teaching and learning.

\section{REFERENCES}

1. Allen, I. Elaine and Jeff Seaman. "Sizing the Opportunity: The Quality and Extent of Online Education in the United States, 2002-2003.” The Sloan Consortium, 2003. Available online: http://www.sloan-c.org/resources/survey.asp.

2. National Center for Education Statistics. Distance Education at Degree-Granting Postsecondary Institutions: 2000-2001. NCES Number: 2003017 Release Date: July 18, 2003. Available online: http://nces.ed.gov/surveys/peqis/publications/2003017/.

3. Astuto, T. A., D. L. Clark, A. M. Read, K. McGree, \& L. deK. P. Fernandez. Challenges to dominant assumptions controlling educational reform. Andover, Massachusetts: Regional Laboratory for the Educational Improvement of the Northeast and Islands, 1993.

4. Louis, K. S. \& S. D. Kruse. Professionalism and Community: Perspectives on Reforming Urban Schools. Thousand Oaks, California: Corwin Press, 1995.

5. Carnevale, D. For Online Adjuncts, a Seller's Market. Part-time professors, in demand, fill many distance-education faculties. Chronicle of Higher Education 50 (34): April 30, 2004.

\section{ABOUT THE AUTHORS}

Maria Puzziferro-Schnitzer is the Associate Dean for Virtual College at Florida Community College at Jacksonville. She also teaches online and blended courses. She earned a B.A. in Political Science from Adelphi University in 1993, a M.A. in Public Administration and an M.L.S. from St. John's University in 1996, and is currently conducting research on student success in online courses to complete her Ph.D. in Administration, Leadership and Technology at New York University. 
Jeff Kissinger is the Instructional Program Manager for Virtual College at Florida Community College at Jacksonville. In his current role he is responsible for the college course repository and works on various college-wide course development projects that includes the Military Education Institute. He also teaches online courses in Education and multimedia. He received a B.A. in English, M.A. in Instruction \& Curriculum, and M.A. in Special Education, all from the University of Florida. He is currently pursuing his Ed.D. at the University of Florida. 